\title{
Isolation and Identification of Aryl Hydrocarbon Receptor Modulators in White Button Mushrooms (Agaricus bisporus)
}

Yuan Tian ${ }^{\dagger},+,{ }^{\ddagger}$ Wei Gui ${ }^{\dagger},{ }^{\prime}$, Philip B. Smith ${ }^{\S}$, Imhoi Koo ${ }^{\dagger}$, Iain A. Murray ${ }^{\dagger}$, Margherita T. Cantorna $^{\dagger}$, Gary H. Perdew ${ }^{\dagger}$, and Andrew D. Patterson ${ }^{\dagger}{ }^{\dagger}$

†Department of Veterinary and Biomedical Sciences, The Pennsylvania State University, University Park, Pennsylvania 16802, United States

\$CAS Key Laboratory of Magnetic Resonance in Biological Systems, State Key Laboratory of Magnetic Resonance and Atomic and Molecular Physics, National Centre for Magnetic Resonance in Wuhan, Wuhan Institute of Physics and Mathematics, University of Chinese Academy of Sciences, Wuhan, 430071, P. R. China

§Huck Institutes of the Life Sciences, The Pennsylvania State University, University Park, Pennsylvania 16802, United States

\# $_{\text {These authors contributed equally to this work }}$

* To whom correspondence should be addressed. Email: adp117@psu.edu. Address: 322 Life Science Bldg, University Park, PA 16802, Phone: 814-867-4565 
Table S1. mRNA gene-targeted primers used in this study

\begin{tabular}{|c|c|c|}
\hline Gene & Abbreviation & Sequence (5'-3') \\
\hline Ribosomal protein L13 & $R p l 13$ & $\begin{array}{c}\text { TAC CAG AAA GTT TGC TTA CCT GGG } \\
\text { TGC CTG TTT CCG TAA CCT CAA G }\end{array}$ \\
\hline Glyceraldehyde-3-phosphate dehydrogenase & Gapdh & $\begin{array}{r}\text { CCT CGT CCC GTA GAC AAA ATG } \\
\text { TGA AGG GGT CGT TGA TGG C }\end{array}$ \\
\hline Cytochrome P450, family 1, member A1 & CYP1A1 & $\begin{array}{c}\text { CTC TTC CCT GGA TGC CTT GAA } \\
\text { GGA TGT GGC CCT TCT CAA ATG }\end{array}$ \\
\hline Cytochrome P450, family 1, member A2 & CYP1A2 & $\begin{array}{c}\text { GCC CCT GCC CTT CAG TGG TAC AG } \\
\text { AGG AGT GGA GCC GAT GCG GA }\end{array}$ \\
\hline Aryl-hydrocarbon receptor repressor & AHRR & $\begin{array}{c}\text { GTG CGA ATC GGA ACT GCA TGG AAA } \\
\text { TCA GTC TGT TCC CTG AGC ACC AAA }\end{array}$ \\
\hline
\end{tabular}




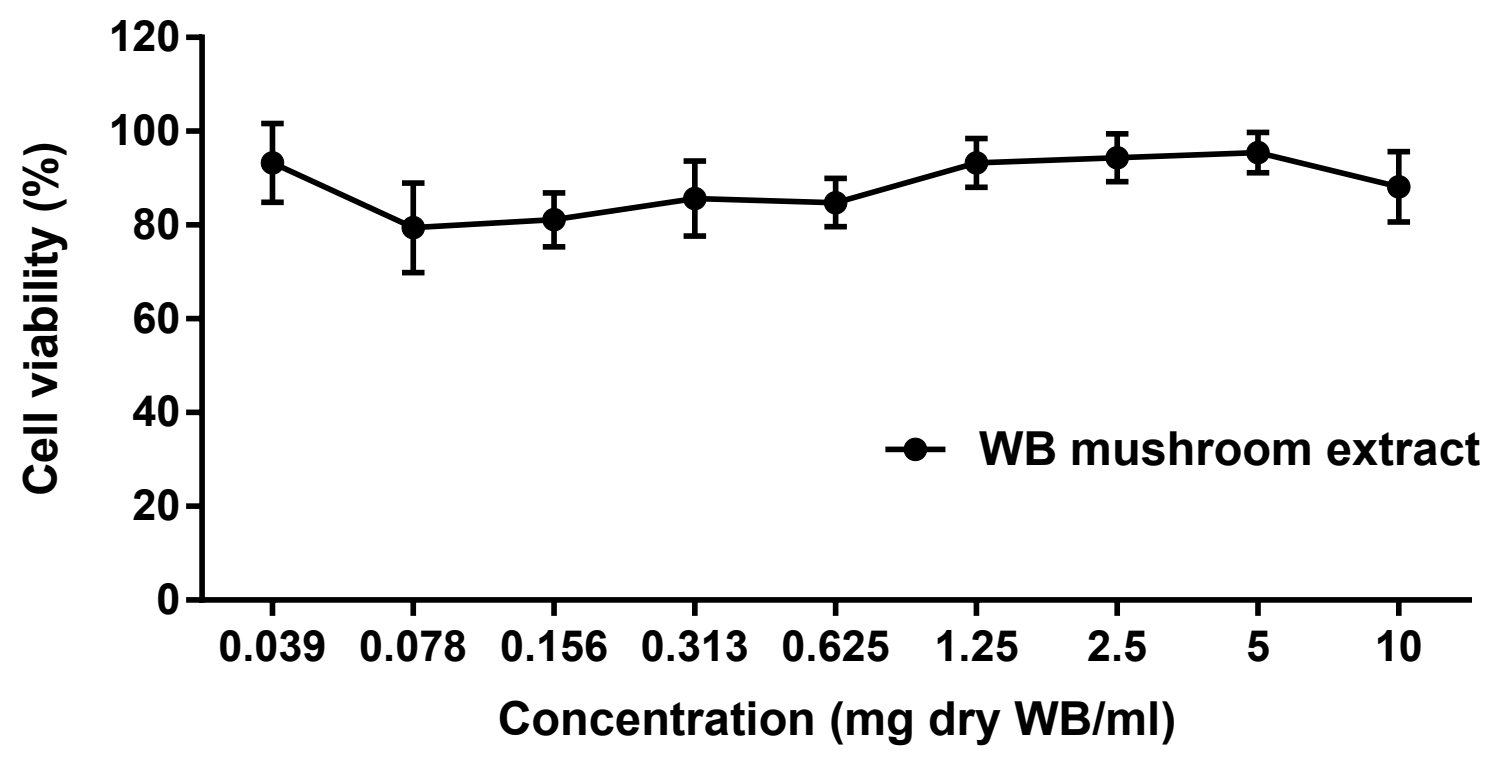

Figure S1. Percent viability of HepG2 40/6 cells measured by MTT assay after exposure for 5 hours to various dilutions of WB mushroom extract. Values are the mean \pm S.D. of $n=3$ per group. 

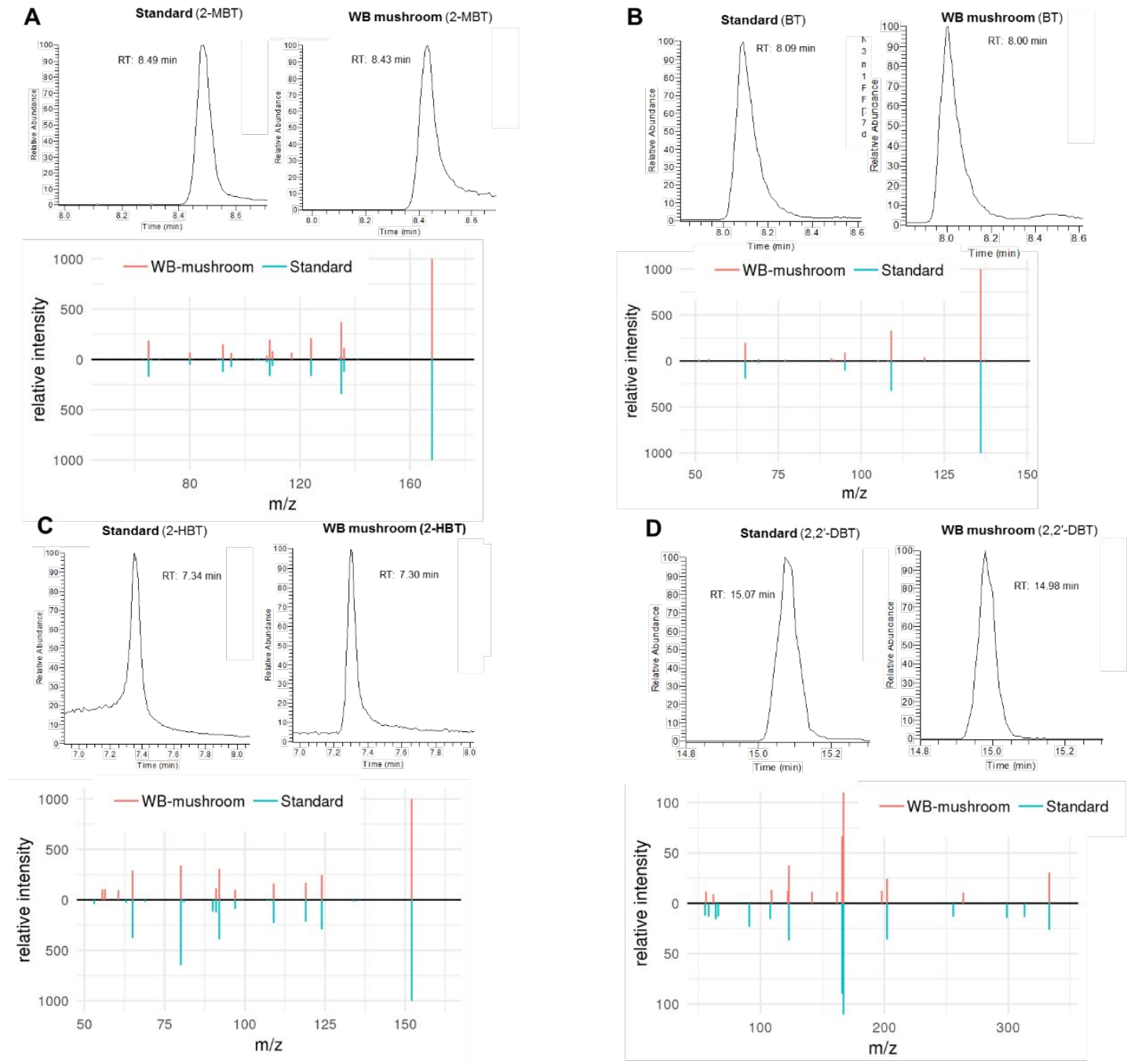

Figure S2. UHPLC/MS-MS chromatograms of standard (A) 2-mercaptobenzothiazole (2-MBT), (B) benzothiazole (BT), (C) 2-hydrobenzothiazole (2-HBT), and (D) 2,2'-Dithiobis(Benzothiazole) (2,2'-DBT) and from WB mushroom extract. 

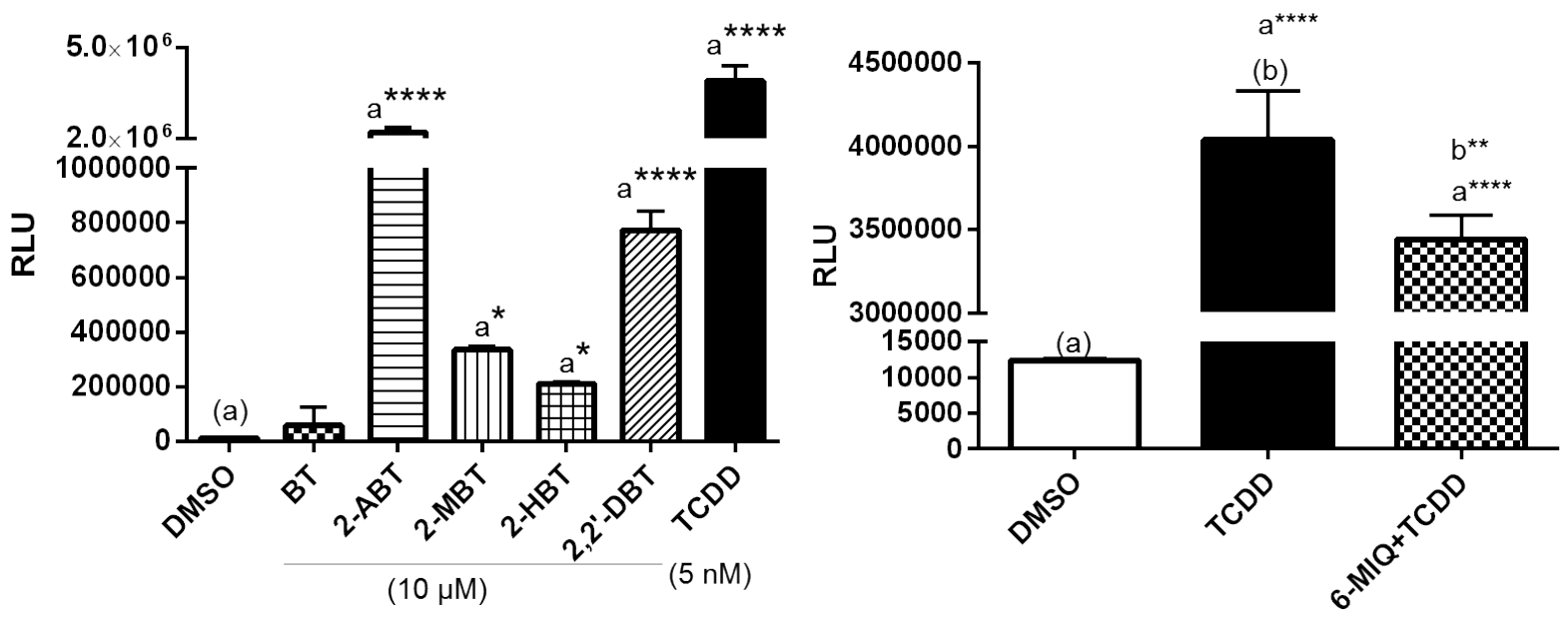

Figure S3. AHR modulator activity of $10 \mu \mathrm{M}$ identified compounds. Hepa 1.1 reporter cells were treated with compounds alone or with $5 \mathrm{nM}$ TCDD for $5 \mathrm{~h}$. Values are the mean \pm S.D. of $\mathrm{n}=3$ per group. ${ }^{*} \mathrm{p}<0.05,{ }^{* *} \mathrm{p}<0.01,{ }^{* * * *} \mathrm{p}<0.0001$ 

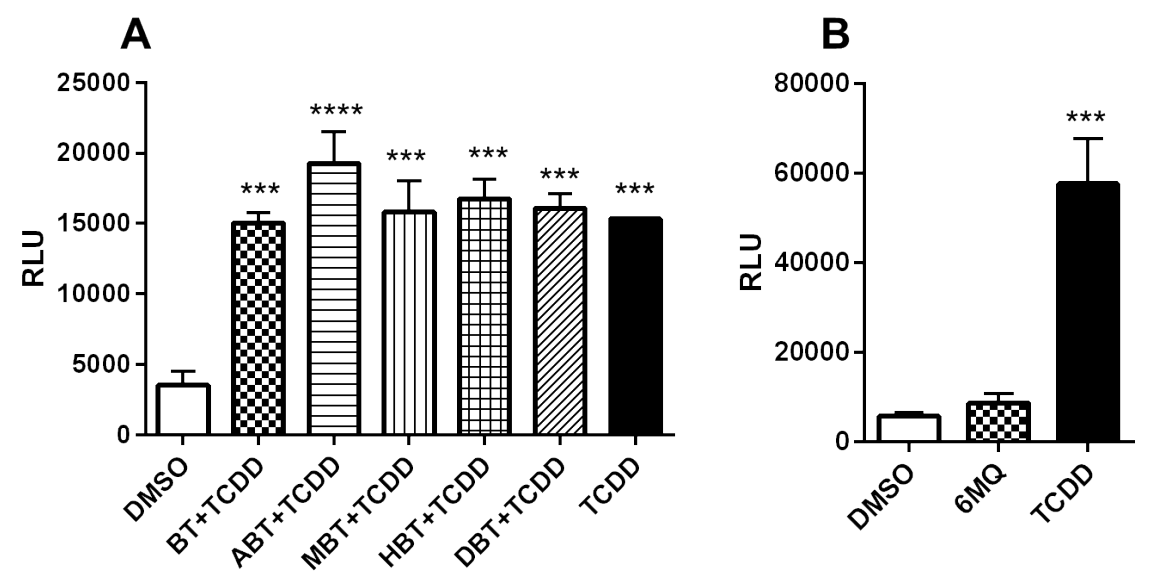

Figure S4. (A) AHR antagonistic activities of BT derivatives. HepG2 40/6 reporter cells were treated with $5 \mathrm{nM}$ TCDD and $10 \mu \mathrm{M}$ of BT derivatives for $5 \mathrm{~h}$. (B) AHR agonistic activity of 6MIQ. HepG2 40/6 reporter cells were treated with 6-MIQ alone or $5 \mathrm{nM}$ TCDD for $5 \mathrm{~h}$. Values are the mean \pm S.D. of $\mathrm{n}=3$ per group. $* * * \mathrm{p}<0.001, * * * * \mathrm{p}<0.0001$ 

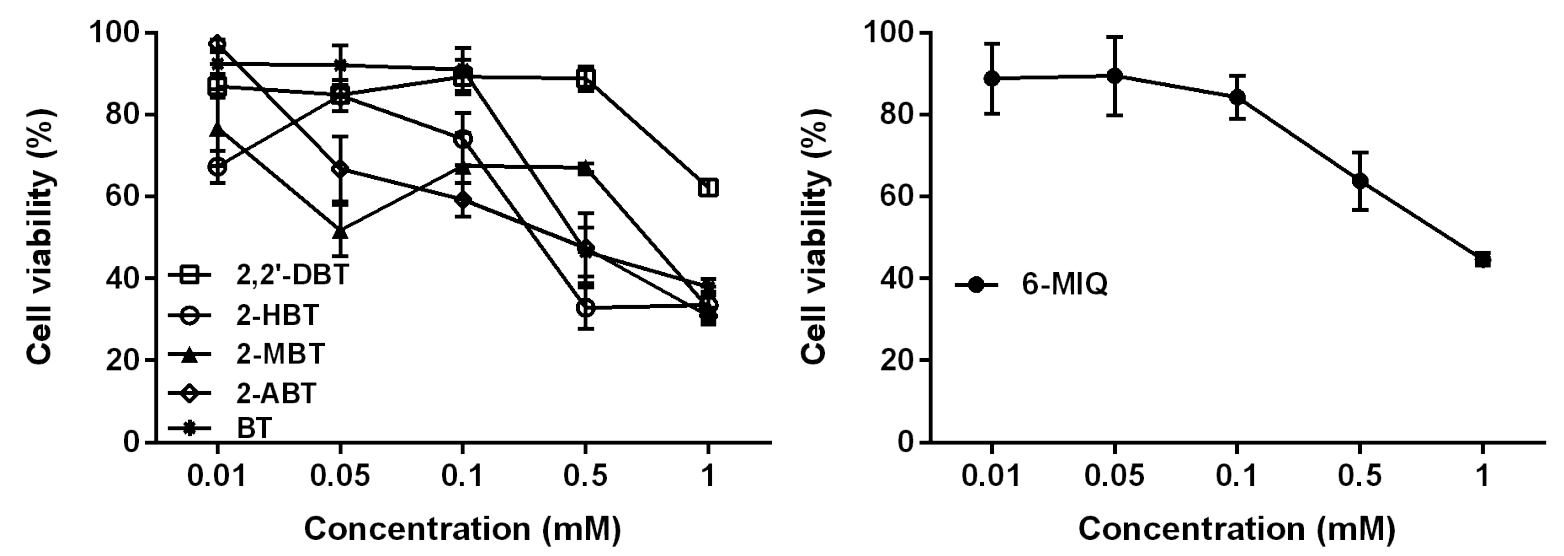

Figure S5. Percent viability of HepG2 40/6 cells measured by MTT assay after exposure for 5 hours to various concentrations of AHR modulators. Values are the mean \pm S.D. of $n=3$ per group. 